\title{
Sobre as origens dos valores de /e/ átono em posição medial no Português europeu e brasileiro ${ }^{1}$
}

\author{
Maria José Carvalho \\ Faculdade de Letras da Universidade de Coimbra (CELGA-ILTEC)
}

Data de recepción: 12/04/2015 | Data de aceptación: 22/06/2015

\begin{abstract}
Resumo:
O objetivo deste artigo é demonstrar que a elevação de /e/ átono em posição interior de palavra é um fenómeno muito antigo na língua portuguesa, remontando já ao século XIII. De facto, prova-se que, independentemente dos condicionamentos vocálicos assimilatórios já referidos por Herculano de Carvalho (1962), houve uma tendência primitiva para /e/ se elevar, num grande número de lexemas, tendo tido a proximidade articulatória de certos fonemas consonânticos um papel importante na valoração ou rejeição social dessa elevação e na sua integração na modalidade standard. Para além dessa tendência, também já no início do século XIV, registam-se testemunhos de redução para [i] desse /e/ átono (eventualmente segundo a evolução $[\mathrm{e}]>[\mathrm{i}]>[\mathrm{i}]$ ), à semelhança do que acontece no PE contemporâneo. Assim, a cronologia deste fenómeno, que costuma situar-se no século XVIII, de acordo com Carvalho e Teyssier (1980), deverá ser recuada para cerca de quatro séculos.
\end{abstract}

\section{Palavras-chave:}

Vocalismo átono, Harmonização vocálica, Vocalismo átono no Português europeu, Vocalismo átono no Português brasileiro, Fonética histórica do Português.

\section{Sumário:}

1. Introdução. 1.1. Status quaestionis. 1.2. Vantagens de um corpus documental, cronologicamente seriado. 2. Análise do corpus. 2.1 /e/ átono em posição inicial absoluta. 2.2. /e/ átono em posição pretónica (não inicial absoluta). 2.2.1.Condicionamentos consonânticos que conduzem ao fechamento do timbre da vogal pretónica. 2.2.2 Condicionamentos (simultaneamente consonânticos e vocálicos) que conduzem ao fechamento do timbre da vogal pretónica. 2.2.3. Elevação de /e/ devido à harmonização vocálica. 2.3 Difusão da realização [i] para /e/ átono . 2.4. /e/ átono em posição pretónica, em hiato com a vogal tónica. 2.5 /e/ átono em posição postónica, e em hiato com a vogal tónica. $2.6 / \mathrm{i} / \sim / \mathrm{e} / \mathrm{em}$ posição final não absoluta: terminação -uil/-uel. 3. Conclusões. Referências bibliográficas.

1 Este artigo constitui uma versão melhorada de uma secção da tese de doutoramento da Autora, apresentada à Faculdade de Letras da Universidade de Coimbra (Carvalho 2006: 343-364), inédita. Quanto à posição átona final, e para o domínio português (onde [i] final ainda sobrevive, nomeadamente nos falares do Alentejo, Castelo Branco e Portalegre), veja-se Carvalho (2005: 47-60). Consulte-se, também, Mariño Paz (2009: 71-98), sobre a evolução do fenómeno no galego medieval. 


\title{
On the origins of the values of unstressed non-final /e/ in European and Brazilian Portuguese
}

\begin{abstract}
:
The aim of this article is to show that the raising of unstressed le/ within a word is a very early feature of Portuguese, dating from the $13^{\text {th }}$ century. In fact it can be shown that, independent of the assimilatory vocalic conditions mentioned by Herculano de Carvalho (1962), there was an early tendency for lel to rise in a large number of lexemes, with the articulatory proximity of certain consonantal phonemes playing an important part in the social acceptance or rejection of this elevation and of its integration into the standard variety. In addition to this tendency, there is evidence from the early $14^{\text {th }}$ century of reduction of unstressed le/ to [i] (possibly according to the evolution [e] > [i] > [i]), similar to what happens in contemporary European Portuguese. The chronology of this phenomenon, which is often said to be in the $18^{\text {th }}$ century, according to Carvalho and Teyssier (1980), therefore needs to be put back by about four centuries.
\end{abstract}

\section{Key words:}

Atonic vocalism, Vocalic harmonization, Atonic vocalism in European Portuguese, Atonic vocalism in Brazilian Portuguese, Portuguese historical phonology.

\section{Contents:}

1. Introduction. 1.1. State of the art. 1.2. Advantages of a chronologically arranged corpus. 2. Analysis of the corpus. 2.1. Unstressed le/ in absolute initial position. 2.2. Unstressed lel in pretonic position (not absolute initial). 2.2.1. Consonantal environment leading to closure of the quality of the pretonic vowel. 2.2.2. Environment (both consonantal and vocalic) leading to closure of the quality of the pretonic vowel. 2.2.3. Raising of le/ due to vowel harmonization. 2.3 Spread of the realization [i] for unstressed /e/. 2.4. Unstressed lel in pretonic position, in hiatus with the tonic vowel. 2.5 Unstressed lel in posttonic position, and in hiatus with the tonic vowel. $2.6 / \mathrm{i} / \mathrm{\sim} / \mathrm{e} / \mathrm{in}$ non-absolute final position: termination -uil/-uel. 3. Conclusions. Bibliographic references. 


\section{Introdução}

\subsection{Status quaestionis}

Como é sabido, em Português europeu contemporâneo, /e/ em sílaba átona realiza-se, normalmente, como [i] (obediente), [i] (passear) ou pode, simplesmente, omitir-se ([ø]), não tendo valor fónico (esquecer). No Português do Brasil, à exceção dos casos em que se verifica o fenómeno da harmonização vocálica (pidir), a realização

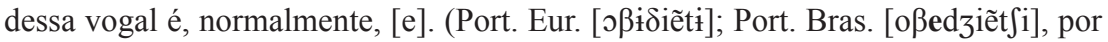
exemplo).

$\mathrm{O}$ interesse manifestado pela determinação do valor fónico de $e$ átono no Português medieval tem sido proporcional ao esforço em detetar nas nossas primeiras gramáticas algumas pistas para esclarecer esta questão simultaneamente tão obscura e importante. Todavia, os autores reconhecem com algum desencanto as limitações dessas obras enquanto fontes de estudo para algumas mudanças linguísticas registadas no português medieval. Assim, Jacinto do Prado Coelho alerta-nos para o "nacionalismo linguístico" de Fernão de Oliveira, que nos deverá pôr de sobreaviso (Coelho 1946: 219), ao passo que Thomas R. Hart, a propósito do valor de $e$ e $o$ átonos, "the most difficult of all the problems connected with the reconstruction of sixteenth-century Portuguese pronunciation», reconhece que «the contemporary grammarians are of very little help" (Hart 1955: 409). Sobre a mesma ambiguidade reflete Herculano de Carvalho, acabando por questionar os gramáticos e ortógrafos, que, não obstante se revelarem bons observadores, não possuíam "a disciplina teórica" de discípulos de Trubetzkoy. Admite, assim, que a sua perspetiva era explicitamente ortográfica, alicerçando-se na convicção "de uma precedência, se não cronológica, pelo menos hierárquica ou axiológica, da imagem gráfica, escrita, sobre a imagem sonora, falada (...)" (Carvalho 1962: 4). Segundo este Autor, no português antigo (pelo menos até ao século XVIII e na língua culta de Lisboa) correspondia a [e] o $e$ da sílaba pretónica, ainda que se apresentasse em hiato:

Destas observações parece pois dever concluir-se inequivocamente que no princípio do século XVIII, ao menos na variedade idiomática representada por D. Luís Caetano (natural de Lisboa), os grafemas átonos e o equivaliam (...) sempre aos fones vocálicos [e] e [o], mesmo em sílaba final, mesmo em hiato (...) (Carvalho 1962:13-14). 
E, em outra passagem, reitera: "quanto às outras posições (em morar, dever, árvore, áspero), teremos que supor, até nova prova, que e o correspondessem efetivamente a [e o] fechados, e não ainda a [ë u]" (Carvalho 1962: 15).

A mesma opinião quanto à cronologia da redução de $e$ pretónico partilha Paul Teyssier (1980: 78), ${ }^{2}$ embora complexificando um pouco mais a questão da sua origem. De facto, parece estar em concordância com os dados colhidos neste corpus a hipótese, admitida por este autor, segundo a qual o [i] pretónico deve ter passado por uma fase intermédia [i], tal como em posição final átona. Ora, tendo em conta os conceitos de língua como "sincronia dinâmica" ou "diassistema", de filiação coseriana, não devemos entender essas variantes com $i$ como correspondendo a tipos de língua "marcados", neste caso da zona Centro-meridional. ${ }^{3}$ De facto, exprime-se, deste modo, o autor francês:

La prononciation brésilienne perpétue donc sur ce point encore celle du Portugal avant les grandes mutations phonétiques du XVIIIe siècle. Bien plus, le "brésilien" pratique certaines des transformations exceptionnelles des prétoniques que connaissait également la vieille langue, par exemple entrar et estar prononcés comme intrar et istar, ou menino et costume prononcés comme minino et custume. Dans ce cas l'alternative est entre [ẹ] et [i]: le "brésilien" ignore absolument, en quelque position que ce soit, la voyelle centrale [ë] si caractéristique du Portugal (Teyssier 1980: 103).

Baseado em Paul Teyssier, Ivo Castro refere que «a elevação das vogais átonas pré-tónicas mediais generalizou-se em português durante a primeira metade do século XVIII, se bem que deva ter começado, talvez, logo no século anterior» (Castro 1991: 259).

Recorrendo aos exemplos citados por Fernão de Oliveira, prossegue, desta forma, Herculano de Carvalho:

De resto um fenómeno assimilatório perfeitamente idêntico está também amplamente documentado para $e$ pretónico, fechado em $i$ por efeito de um $u$ ou $i$ da sílaba seguinte, em numerosos textos dos mesmos séculos: recibido, pitiçom, minino, pidir, testimunha (Carvalho 1962: 16).

Ivo Castro afirma que se trata de "elevações motivadas por uma pressão assimilatória (...)" e que "a elevação setecentista é de uma natureza diferente, pois ocorre

2 Refere o autor: "Le [ë] pretonique si caractéristique de la langue contemporaine du Portugal est apparu au XVIII ${ }^{\mathrm{e}}$ siècle, vraisemblablement après 1750" .

3 Referimo-nos, neste caso, ao $i$ final, que já estudámos em outra ocasião, como foi referido anteriormente. 
independentemente do contexto sintagmático" (Castro 1991: 259). Ao descrever a língua portuguesa no tempo do Infante D. Pedro, o mesmo autor confirmaria, dois anos depois, que se tratou de uma mudança que caracterizou a língua dos séculos XVII e XVIII (Castro 1993: 100).

\subsection{Vantagens de um corpus documental, cronologicamente seriado}

O corpus analisado é constituído por 153 documentos notariais originais (sécs. XIII-XVI), por nós transcrito (Carvalho 2006: 33-287), oriundo dos fundos do mosteiro cisterciense de Alcobaça, um importante centro na cultura portuguesa medieval (situado entre Coimbra e Lisboa). Os documentos situam-se num período compreendido entre 1289 e 1565, e são redigidos não apenas no mosteiro mas também nas áreas periféricas sob sua jurisdição, os chamados “coutos". Escolhemos como amostra um corpus único, seriado cronologicamente, pois cremos que é comparando textos do mesmo género ao longo dos tempos que chegamos ao que Kabatek designou de variação diacrónica "autêntica" (Kabatek 2001: 97). O universo do discurso é a linguagem jurídica usada nos contratos relativos à propriedade: documentos de compra e venda, de arrendamento, de troca, recibos e testamentos, por exemplo. É sobre esta dupla base de campo de estudo - geográfica e temática que podemos observar a evolução contínua dos textos e, por isso, em paralelo, da língua.

Como demonstraremos adiante, a redução e fechamento das vogais átonas mediais do Português europeu contemporâneo, fonte dos maiores embaraços na produção/perceção desta modalidade por parte de um falante/ouvinte estrangeiro, encontra-se já documentada em textos do século XIII e primeiros anos do século seguinte. De facto, os nossos dados evidenciam a realização [i] para $e$ pretónico não só em formas em que se verificam condicionamentos vocálicos assimilatórios (como foi demonstrado por Herculano de Carvalho) mas, e sobretudo, também consonânticos (tendo, frequentemente atuado os dois tipos de contexto), pelo que tentaremos provar que se trata de uma mudança intra-linguística (através da difusão léxica) cujo ponto de partida remonta ao século XIII, havendo mesmo lexemas, no corpus em análise, que nunca apresentaram a vogal $e$. Também apresentaremos dados que evidenciam que o [i] do Português europeu remonta ao século XIV, época em que se encontrava em fase de incubação, em determinados contextos. 


\section{Análise do corpus ${ }^{4}$}

\section{1 /e/ átono em posição inicial absoluta ${ }^{5}$}

Nesta posição, $e$ alterna, por vezes, $\operatorname{com} j, y$, e com o ditongo $e i$, situação que é comum ao corpus de $H G P^{6}$ e cuja cronologia depende, no nosso ponto de vista, do tipo de lexema. Há uma forma que regista sistematicamente $e$ desde princípios do século XIV até finais do século XV: ereeos 'herdeiros' (1496 Sal 135), h[er]ees (1345 MA 33; 1397 MA 63, 2 v.) e heréés (1307 Alp 13; 1332 Alc 24) (< HERĒDES).

O inverso ocorre com as formas historicamente resultantes de GERMANU- e GERMANA-, que nunca surgem no nosso corpus com $e$ inicial, nem mesmo nas etapas mais recuadas da língua. Tal fenómeno poderá dever-se ao facto de a vogal em causa constituir núcleo de sílaba entravada por vibrante ${ }^{7}$, mas em ermitã (1307 Alp 13), proveniente de EREMITĀNU, igualmente com vibrante nesse contexto, esse fechamento apenas atuou em épocas tardias, como se pode verificar pela abonação abaixo citada. De qualquer forma, excetuando as formas jrmááljrmão e variantes, só a partir do terceiro quartel do século XV é que se começam a registar abonações com $j$ (esporadicamente $y$ e $z$ ) em posição inicial absoluta, mas os exemplos recolhidos nessas circunstâncias são escassos para poder traçar cronologias seguras:

Zdeficada (1477 MA 121)8, hyrmaão (1437 Ped 94), jrmáá (1343 AM 31; 1343 Cós 32), jrmaão (1405 MA 70; 1438 Ped 95, 2 v.), jrmaao (1450

4 A identificação do documento é feita de acordo com o seguinte critério: data, local de redação (sigla ou acrónimo; ex: Alv = Alvorninha) e número, dentro da nossa coleção.

5 Ocasionalmente, e apenas em documentos de épocas mais tardias, surgem outras formas de reforço da vogal átona inicial, como, por exemplo, $a$ no lugar de $e$ inicial, por atuação de fenómenos de tipo assimilatório ou dissimilatório. Estão nesse caso as formas adeficaffe (1477 MA 121), afqeuardes (com permuta de vogais) 'escavardes' (1375 MA 48), auãgelhos (1487 PP 129, 2 v.) e avãgelhos (1515 SM 141). Encontrámos a forma euãgelhos em época bastante anterior (1415 Ped 77). No documento de 1477, ao lado de adeficaffe, podemos observar igualmente as formas Zdeficada, edeficada (3v.) e edeficar. Esporadicamente, a vogal átona nesse contexto, quando nasal, pode oscilar com $a$ também nasal (por vezes, com ditongo nasal), à semelhança do que ainda hoje ocorre na linguagem popular. Essa tendência acentua-se em textos do século XVI: Amryque (1541 Sal 152, 3 v.), amtrellynha (1541 Sal 152), Anrique (1502 MA 137, 3 v.), Anrriqe (1346 Tur 35), antrelinha (1451 MA 105), antreljnha

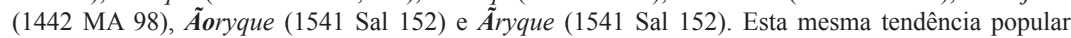
poderá igualmente encontrar-se no galego atual (Ferreiro 1999: 52).

6 Este acrónimo será doravante usado para referir a obra História do galego-português (Maia 1997).

7 Esta proposta explicativa não é, contudo, incompatível com a de outros autores como García de Diego, para quem "e puede á veces debilitarse en $i$, acaso por influencia del acento secundario" (1909: 18), ou, ainda, Ferreiro, que considera que "a fonética sintáctica puido influír para esta evolución ao quedar en contacto a vogal $e$ - cunha vogal forte anterior, normalmente o artigo" (Ferreiro 1999: 51).

8 No mesmo documento encontra-se edeficada (3 v.), edeficar e adeficaffe. 
Alv 104), jrmão (1437 Ped 94; 1455 MA 108, 4 v.; 1565 Alc 153), jrmãoo (1490 MA 131, 3 v.; 1495 MA 134; 1507 MA 139, 2 v.),jrmãos (1565 Alc 153, 4 v.),jrmỹtã (1532 Tur 149), jfamjnado (1472 TC 120), jfatas (1496 Sal 135), jrmjda (1505 MA 138), jftipolant[e] (1490 MA 131), jftipulaçam (1490 MA 131), ${ }^{9}$ jftipulant[e] (1490 MA 131) e yrmaão (1438 Ped 95).

A única forma que nos parece decisiva para estabelecer a cronologia do fechamento desta vogal átona em posição inicial absoluta é a que é historicamente representante de ECCLESIA-, com $e$ seguido de consoante articulatoriamente bastante afastada desta vogal ${ }^{10}$. Só a partir da segunda metade do século XV é possível observar uma mudança sistemática no uso do(s) grafema(s) que representa(m) a vogal em causa. Essa mudança gráfica parece não deixar dúvidas de que, nessa posição, /e/ começava a corresponder, já não a [e] mas a [i], na oralidade. Observemos o seguinte gráfico: ${ }^{11}$

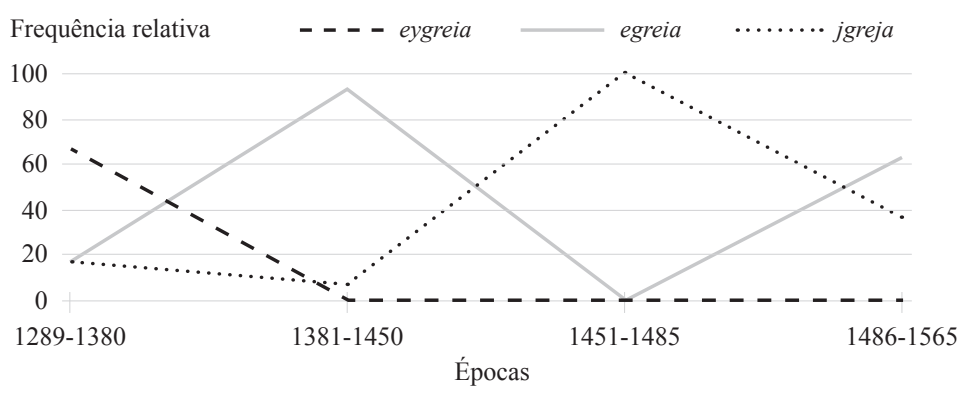

Figura $\mathrm{n}^{\circ} 1$ - Distribuição temporal das variantes com $e y, e$ e $j(y$ e $i)$ na forma igreja

Para além de $e$ e $j$ (esporadicamente, $y$ ), os documentos agora analisados apresentam igualmente ei ou ey na sílaba átona inicial, desde finais do século XIII ${ }^{12}$. Podem observar-se os seguintes exemplos:

9 No mesmo documento encontra-se eftipulaçam.

10 A hipótese avançada por Ferreiro relativamente ao item lexical irmão (influência da fonética sintática) aplica-se igualmente a igreja (Ferreiro 1999: 51). Vejam-se, a este propósito, a multiplicidade e o polimorfismo fónico e gráfico das variantes expostas por Boullón Agrelo 2013: 69. O nosso estudo não inclui formas resultantes do desdobramento de abreviaturas.

11 No período compreendido entre 1486 e 1565 registam-se apenas 2 exemplos de $y$; por outro lado, a variante com $e$, durante esse período, surge apenas em dois documentos do mesmo tabelião (em Aljubarrota), que usa esse grafema como tendência dominante, em 1491. Cremos, contudo, que já não teria a realização fónica [e], uma vez que no segundo documento se regista também ygreja, o que comprova a hesitação gráfica perante um fenómeno de mudança já consumado.

12 No galego existe ainda uma esporádica vacilação ei ai na forma igrexa, da linguagem comum (eirexa/ airexa sobrevivem ainda dialetalmente). Consulte-se Ferreiro 1999: 80-81. 
eixacuçõ (1351 Alv 37), eixacuçoes (1351 Alv 37, 2 v.), eixecuçõ (1405 MA 70), eixucaçã (1422 MA 82), eixucaçã (1429 MA 88), eyceyções (1328 Alj 21), eygrega (1297 Cós 4), eygreia (1289 MA 1; 1379 Alc 51, 2 v.), eyfeyçõ (1328 Alj 21, 2 v.), eyxertos (1500 MA 136), eyxucaçom (1507 MA 139) e еухисис̧о̃ (1500 MA 136).

Recorde-se que, na sequência da explicação dada por Menéndez Pidal a propósito do leonês, exprime-se deste modo a Autora de $H G P$ :

as formas com ditongo inicial ei- (ou ey-), ainda que não muito numerosas, são indício de uma tendência que, manifestando-se ainda actualmente em mirandês, no asturiano ocidental e nalguns falares trasmontanos em contacto com falares leoneses, existiu também em antigo galego-português: trata-se da tendência para introduzir o ditongo ei no início de palavra, devido à grande vitalidade do referido ditongo nesses idiomas e à elevada frequência de palavras por ele iniciadas (Maia 1997: 357). ${ }^{13}$

Pode, portanto, concluir-se que, tal como no antigo galego-português, no português da zona Centro do País, que viria a ser identificado como o idioma padrão, /e/ em posição inicial absoluta podia realizar-se como [e], [i] ou [ej]. Parece, de fato, bastante provável que "nem sempre fosse perfeita a relação entre cada um destes tipos de pronúncia e as respectivas formas gráficas: o grafema $e$ encobriria certamente, em muitos casos, pronúncias com $i$ - ou, menos frequentemente, com ei-" (Maia 1997: 358).

Uma tendência para reforçar a vogal átona em posição inicial absoluta parece ter sido a sua nasalização, em muitos casos em formas onde também se regista ei/ey, nesse contexto. Vejamos os seguintes exemplos, registados apenas a partir de finais do século XIV, mas com uma frequência mais acentuada a partir da segunda metade do século seguinte:

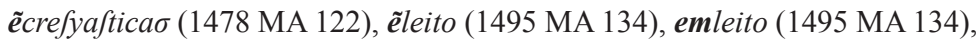
emxeicõ (1477 MA 121), emxequeyas (1491 Alj 133), emxucotor (1491 Alj 133), enlegerẽ (1391 MA 59), enliçom (1391 MA 59), enxucaçã (1502 MA 137), enxucaçom (1495 MA 134), ẽxeiçõ (1478 MA 122, 2 v.; 1478 MA 123; 1479 MA 124; 1484 MA 126; 1485 MA 128), éxucoçõ (1477 MA 121; 1478 MA 122, 2 v.; 1478 MA 123; 1479 MA 124; 1484 MA 126) e ẽxuqueçã (1462 Alj 115).

13 As formas com ditongo ei inicial estão ainda vivas na zona Centro do país em falantes das camadas populares, com baixo nível de instrução. Ouvimos ainda recentemente no distrito de Aveiro a forma exemplo pronunciada como [ej'zẽplu], por um falante do sexo feminino. 
De acordo com Ferreiro, em alguns casos, «o grupo inicial EKs- (“ex-") tivo evolucións paralelas ei-/en- (/e-), impoñéndose maioritariamente na época moderna as formas sem ditongo» (1999: 78 e 134): eixame $\sim$ enxame $>$ mod. enxame, eixuto $\sim$ enxuito $>$ enxuto, port. (gal. enxoito), eixerdar $\sim$ enxerdar (med.), eixempro $\sim$ enxempro $\sim$ exempro (med. e pop.).

Por outro lado, en em posição inicial teve tendência a elevar-se, podendo igualmente oscilar com vogal nasal anterior fechada, também em textos mais tardios: jmfermeiro ${ }^{14}$ (1528 MA 147), jnfatiotos 'enfitêuse' (1482 MA 125), jnfermeiro (1527 MA 146),

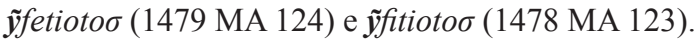

Estes dados parecem dar alguma credibilidade às afirmações de Naro, embora a "ordem" cronológica dos fenómenos seja opinável, pois não parece condicente com os nossos dados o fenómeno da desnasalização de [ĩ] em [i]. Segundo o Autor, a realização [i] em posição final resultaria da generalização, para a forma de "imagem reflectida" (Naro 1971: 639 e sgs.), de uma regra que elevava [e] inicial de palavra para [i]. Na origem desta última regra estaria a confusão entre vários prefixos que levou ao aparecimento, a partir do século XVI, de variantes de [e] inicial pré-consonântico: com nasalização, [ẽ], com nasalização e elevação, [ĩ], com elevação e desnasalização, [i]. O padrão europeu bem como alguns dialetos do português do Brasil ter-se-iam fixado na forma [i]. A verdade é que, tal como já referiu Ana Maria Martins, a existência de dialetos, tanto em Portugal como no Brasil, em que /e/ inicial não se realiza como [i], "levanta dificuldades a esta hipótese" (Martins 2003-2007: 301, n. 8).

\section{2. /e/ átono em posição pretónica (não inicial absoluta) ${ }^{15}$}

Tentaremos agora determinar o valor de $e$ em posição pretónica não inicial absoluta, contexto em que a vogal anterior média apresenta grande instabilidade gráfica.

Tal como acontece em posição átona inicial absoluta, também em posição interior se pode registar (embora esporadicamente) junto da vogal o desenvolvimento de uma semivogal, formando-se, assim, um ditongo. Estão nesse caso as formas fufeyçore

14 Registámos a forma emfermeiro (1416 MA 78), num texto de uma fase um pouco mais recuada. Mesmo no século XVI, as formas citadas conviveram com as variantes emfermeiro (1529 MA 148) e emffremeiro (1522 MA 144), presentes em outros textos.

15 Nos começos da escrita documental em galego, era frequente a alternância $e / i$, não só em posição pretónica como em posição inicial (Lorenzo 2007: 319; Boullón Agrelo / Monteagudo 2009: 27-28). 
(1291 Alc 2) e freyguefia ${ }^{16}$ (1385 MA 54), que não ultrapassam, como se vê, o século XIV.

Na sequência do que foi exposto no "Status quæstionis", distinguiremos, assim, vários tipos de situações: aquelas em que existem vários tipos de condicionamento que conduzem ao fechamento do timbre da vogal pretónica (consonântico bem como simultaneamente consonântico e vocálico) e as que são decorrentes de fenómenos de harmonização vocálica que conduzem ao fechamento de $e$ em $i$.

\subsubsection{Condicionamentos consonânticos que conduzem ao fechamento do timbre da vogal pretónica}

No corpus analisado, existem lexemas que nunca surgem registados na sua variante com $e$, sendo que, nestes casos, a vogal se apresenta simultaneamente seguida e precedida de palatal e/ou alveolar. Um deles é o representante histórico do patronímico de Geraldo (< lat. tardio GERALDICI); o outro resulta da transformação histórica de POSSESSIŌNEM:

Giral (1346 SC 34), Giraldez (1356 MA 41; 1359 MA 42; 1362 MA 43; 1362 MA 44; 1363 MA 45; 1391 MA 59, 2 v.; 1413 MA 75, 2 v.; 1429 MA 88, 7 v.; 1346 Alf 93), Giraldiz (1328 Alv 20), Giraldo (1366 MA 46), posysam (1529 MA 148), pofifam (1422 MA 81), pofifoes (1350 AM 36), pofifões (1379 Alc 51), po/j/ãm (1532 Tur 149), pof/iffõ (1315 Alj 15, 2 v.), poffiffom (1306 Cós 12; 1388 MA 57; 1399 MA 65, 2 v.), poffyfam (1536 SC 151), pof/yfooes

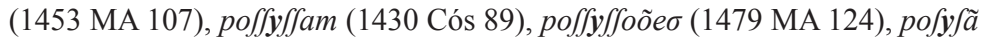
(1509 Ped 140, 2 v.), po/yfam (1462 Mai 114; 1467 Mai 117, 2 v.; 1521 Ped 143), po/y/ãm (1462 Mai 114), po/yfoees (1383 Alj 53), po/yfões (1519 MA 142) e $p o \int \boldsymbol{y}$ fom (1469 Cel 118).

Na tabela seguinte, apresentaremos um conjunto de formas encontradas no nosso corpus que evidenciam o mesmo tipo de condicionamento contextual: o contacto com consoantes palatais ${ }^{17}$ e alveolares:

16 Forma derivada de freguês, cuja etimologia é obscura. José Pedro Machado acha provável que provenha de FILIU-ECCLESIE, ao contrário de Gonçalves Viana, que propõe FILIU- GREGI(s). Num documento do Livro dos bens de D. João de Portel, de 1257, regista-se freyguisia, semelhante à que foi por nós encontrada. Sendo assim, o ditongo verificado nesta forma deverá explicar-se da mesma maneira que em eygreia (< ECCLESIA), analisada anteriormente. Cf. Machado (1995: s. u. "freguês" e "freguesia").

17 Situações deste tipo encontram-se documentadas em HGP: mjlhor, Giraldo, piñor (e derivadas) são as mais abundantemente representadas (cf. HGP, 366-367 e 531). 


\begin{tabular}{ll} 
Data/Doc. & Formas $^{18}$ \\
1291 Alc 3 & ordinhamos \\
1328 Alj 21 & ordinhamos; mjlhor \\
1379 Alc 51 & milhor; hordjnhamos; \\
milhoraredes \\
1388 MA 58 & hordinada \\
1391 MA 59 & ordynações \\
1433 Ped 90 & mjlhor \\
1455 MA 108 & Marichal; coonjgo \\
1505 MA 122 138 & mjlhor \\
1532 Tur 149 & mylhoramẽtos \\
1541 Sal 152 & Ffyrnão \\
1565 Alc 153 & milhor; mylhor (2 v.); mjlhor \\
\hline
\end{tabular}

Tabela $n^{\circ} 1$ - Formas que evidenciam elevação de $e$ pretónico, com condicionamento assimilatório consonântico (de tipo palatal e alveolar)

Os exemplos aduzidos até aqui provam que em formas onde não existe um condicionamento vocálico que conduza aos fenómenos de tipo assimilatório referidos por Herculano de Carvalho, pode verificar-se que o $e$ é, em diferentes épocas do período medieval, substituído por $i$. As formas apresentadas são suficientes para nos autorizar ${ }^{20}$ a afirmar que o fechamento e elevação da vogal átona pretónica é um fenómeno em incubação em épocas recuadas, tendo encontrado condições linguísticas favoráveis, quando em contacto com consoante palatal $(/ \mathrm{n} /, / 3 / \mathrm{e} / \mathrm{K} /)$ ou alveolar $(/ \mathrm{n} /, / \mathrm{r} / \mathrm{e} / \mathrm{s} /)$. Este fenómeno parece ter-se difundido a partir de finais do século XIV. Analisemos, de seguida, as abonações encontradas de formas de pretérito e tempos afins do verbo irregular fazer com vogal radical /i/, resultante da propagação do $i$ tónico da primeira pessoa do pretérito perfeito. ${ }^{21}$

18 Revela-se estranho o facto de nunca termos encontrado formas derivadas de penhora, com fechamento da pretónica, tal como aparecem em $H G P$ (p. 367). Apresentaremos algumas formas que foi possível registar no nosso corpus: apenhorar (1304 Alc 9; 1321 Alc 17; 1324 Alc 18; 1388 MA 58; 1397 MA 63; 1397 MA 64; 1399 MA 66; 1408 MA 71, etc.), enpenhorar (1297 Alc 5), penhora (1397 MA 64; 1399 MA 66; 1403 MA 69; 1408 MA 71; 1409 MA 72; 1410 MA 73, etc.), penhorar (1291 Alc 2; 1332 Alc 24; 1345 MA 33, 2 v.; 1356 MA 41; 1359 MA 42; 1362 MA 43; 1362 MA 44; 1363 MA 45; 1372 MA 47; 1379 Alc 51; 1386 MA 56; 1388 MA 58; 1397 MA 63; 1397 MA 64; 1399 MA 66; 1405 MA 70; 1408 MA 71; 1410 MA 73, etc.), penhoras (1391 MA 59, etc.), penhorede $(1291$ Alc 3), penhoremos (1375 MA 48), etc. Trata-se de um lexema normalmente integrado nas cláusulas jurídicas que, normalmente, apresentam maior resistência à inovação.

19 No mesmo documento encontra-se Ffernão.

20 De acordo com Ivo Castro, "A ausência de testemunhos documentais e a conservação das átonas não elevadas no português do Brasil e nos crioulos de base portuguesa não autoriza o recuo da sua tardia datação" (Castro 1991: 257).

21 As percentagens apresentadas referem-se, naturalmente, à representatividade das formas nos documentos apresentados. Algumas abonações anteriores à primeira data indicada podem encontrar-se em 


\begin{tabular}{llr} 
Data/Doc. & Formas & $\mathbf{\%}$ \\
1386 MA 56 & rrefizerdes & 14 \\
1405 MA 70 & fizeftes & 33 \\
1437 Ped 94 & fyzer & 50 \\
1438 Ped 95 & fizerẽ & 100 \\
1465 MA 116 & fizerdes & 100 \\
1565 Alc 153 & fizesem; satisfizerã; fizerã & 50 \\
\hline
\end{tabular}

Tabela $\mathrm{n}^{\circ} 2$ - Formas do verbo fazer com vogal radical $i$, resultante da propagação de $i$ tónico da $1^{\mathrm{a}}$ pessoa

Parece, de facto, inquestionável que, ainda que se tivessem difundido no segundo quartel do século XV, estas formas "ainda no século XVI alternavam, na língua culta do Centro do País, com as antigas formas com $e$ " (Maia 1997: 368) 22. Nesse documento, para além das três formas com $i$ na vogal do radical, existem outras três que apresentam $e$ etimológico: fezerã $(2 \mathrm{v}$.) e fezese, o que se traduz numa percentagem de $50 \%$, ou seja, exatamente a mesma que se registava num documento de há mais de um século atrás. Tudo leva, portanto, a crer que a grafia ocultava desde há alguns séculos o que se traduzia numa mudança linguística, em curso ou já consumada. De facto, documentos galegos anteriores a 1260 vêm mostrar que «fronte ao devandito queser as máis correntes son as variantes de tipo quis-, abundantemente documentadas» (Boullón Agrelo e Monteagudo 2009: 24).

\subsubsection{Condicionamentos (simultaneamente consonânticos e vocálicos) que conduzem ao fechamento do timbre da vogal pretónica}

Por outro lado, existem ainda aquelas formas em que se verificam simultaneamente os dois contextos assimilatórios, um de tipo consonântico (palatal, alveolar e dental) e outro de tipo vocálico (semivogal anterior da sílaba tónica ou vogal $u$ em sílaba átona ou tónica):

Silva 1998: 115: "O aparecimento das primeiras formas com o lexema FIZ- em pessoas e tempos distintos de IdPt2-P1 acontece, num texto de data aproximada de 1350, fizemos (Um Primo S. Mir. XXXVIII.39) e as seguintes ocorrem em 1377 fizesse (Chart. Universit. II.6.30) e por volta de 1380, fizer (Liv. Falc. 17.10)". Vejam-se, igualmente, as abonações citadas (sobretudo de textos literários) em Gonçalves (1999: XXXII-XXXIII). Quanto aos documentos notariais da zona galego-portuguesa medieval, Clarinda de Azevedo Maia regista apenas a forma fizer (1454 DL 148). Cf. Maia ${ }^{2}$ 1997: 748. À exceção da forma de $1^{\text {a }}$ pessoa tiue (1469 Cel 118), cujo timbre fechado da vogal, resultado da metafonia produzida por $i(<\overline{\mathrm{I}})$, já deverá pertencer à história do latim, não possuímos qualquer inovação nas formas arrizotónicas do perfeito e tempos afins dos verbos estar e ter. De facto, "não se encontram vestígios da propagação do timbre do radical da primeira pessoa do perfeito" (Maia 1997, 839).

22 O último documento do nosso corpus (1565 Alc 153), ao apresentar 50\% de formas com vogal átona $i$ e $50 \%$ com vogal etimológica, revela-se bastante esclarecedor. 


\begin{tabular}{|c|c|c|c|}
\hline Data/Doc. & Influência da (semi)vogal $i$ & Data/Doc. & Influência da vogal $u$ \\
\hline 1315 Alj 15 & teftimoyas; teftimõyo, 2 v.; teftimoyo & & \\
\hline 1379 Alc 51 & ordjnhayro; ordinhayros & 1377 Alv 50 & mjrgulhedes \\
\hline 1402 Ped 68 & hordjnhairo & 1380 Alv 52 & mjrgulhedes \\
\hline 1405 MA 70 & hordjnairo & 1383 Alj 53 & amjrgolhedes \\
\hline 1438 Ped 95 & mjlhorias & 1450 Alv 104 & amjrgulhar \\
\hline 1442 SM 97 & direito; direitos & 1489 MA 130 & teftimunhas \\
\hline 1490 MA 131 & direite; jndireite & 1490 MA 131 & ligumes; teftimunhas \\
\hline $1491 \mathrm{Alj} 133$ & dyreyto & & \\
\hline 1522 MA 144 & pireira; direito & & \\
\hline 1541 Sal 152 & dyrreyto; dyreyto (5 v.) & & \\
\hline
\end{tabular}

Tabela $\mathrm{n}^{\mathrm{o}} 3$ - Formas que evidenciam elevação de $e$ pretónico, com condicionamento assimilatório simultaneamente consonântico e vocálico

Nesta situação, embora seja impossível avaliar o peso relativo de um ou outro condicionamento, cremos que o contexto consonântico se revela extremamente importante, pois só assim se justifica que formas do verbo ordinhar e a forma mjlhor (cf. tabela $\mathrm{n}^{\mathrm{o}}$ 1), onde se registou a elevação da vogal, sejam tão frequentes. Por outro lado, a aceitar que o contexto vocálico assimilatório é por si só responsável pela elevação do timbre da pretónica, seria normal encontrarmos abundantemente representadas no nosso corpus formas como figura e uirtude, uma vez que apresentam vogal $u$ em sílaba tónica. A verdade é que durante todo o período estudado, fegura nunca apresenta $i$ átono (observe-se que $e$ se encontra em contiguidade com um fonema consonântico velar e outro labiodental) e uertude (o $e$ vem seguido de alveolar mas está precedido de labiodental) aparece na variante de tipo moderno, apenas num documento de 1482: ujrtude e uirtude (1482 MA 125).

Destes dados é possível concluir que o contexto consonântico parece ser tão ou mais importante para o fechamento da vogal como o contexto vocálico assimilatório, excetuando-se, como veremos adiante, nos inúmeros casos de assimilação exercida por $i$, que dão origem à harmonização vocálica. Por outro lado, a contiguidade de um fonema consonântico fricativo labiodental ou velar parece ter constituído um contexto fónico que impediu ou (pelo menos) travou, ao longo do período medieval, a elevação de /e/.

Como essa difusão não apresenta a mesma cronologia para todas as unidades lexicais, apresentaremos, em gráficos de linhas, a evolução diacrónica da difusão do timbre fechado da vogal e pretónica em alguns lexemas, selecionando pelo menos um exemplo de cada um dos tipos lexicais e condicionamentos consonânticos já aludidos ${ }^{23}$.

23 Naturalmente que se incluem em cada tipo as variantes gráficas e flexionais. Convém referir que, no caso da grafia $n h$ nas formas ordinhar, ordinhayro(s), inclinamo-nos a pensar que se trata do modo de 


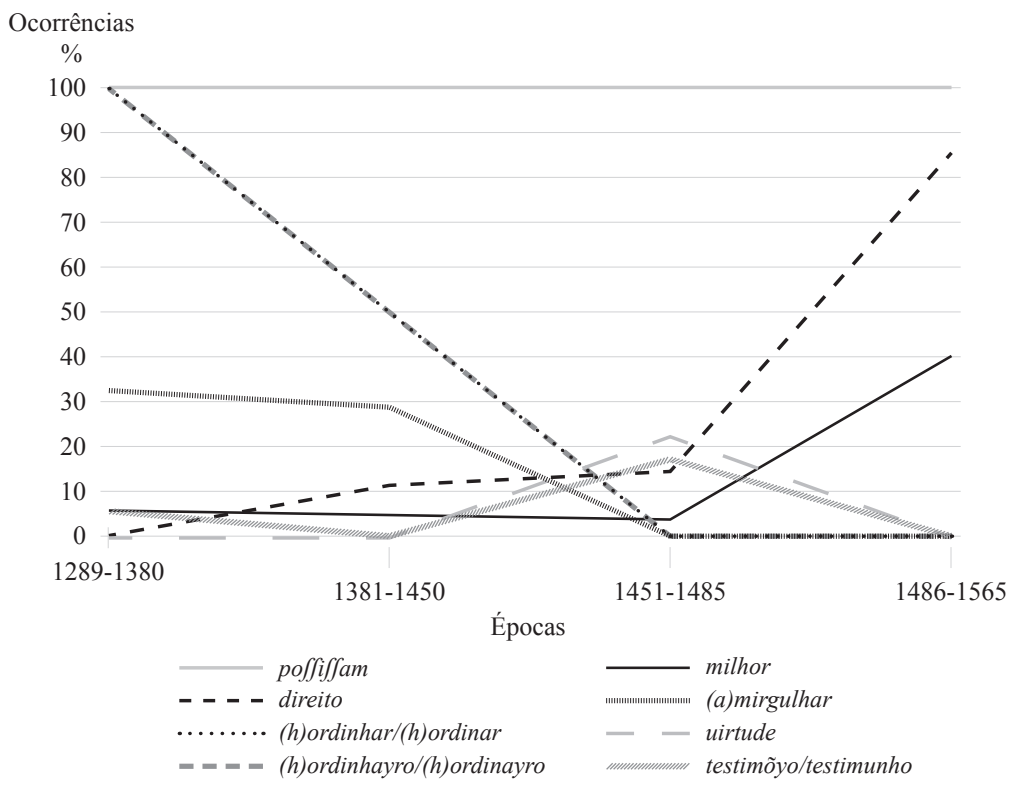

Figura $\mathrm{n}^{\mathrm{o}} 2$ - Cronologias do fechamento para $i$ da vogal anterior pretónica, em vários lexemas e contextos fónicos

Revela-se interessante constatar que formas como (h)ordinhar/(h)ordinar (e seus derivados), tal como (h)ordinhayro e (h)ordinayro, exclusivas até 1380, reduziram-se para $50 \%$ entre essa data e 1450 , extinguindo-se a partir daí ${ }^{24}$. No segundo caso, a partir de 1430, a variante que iria aparecer sistematicamente nos textos seria aquela que exibia $e$ átono: (h)ordenairo(s) (e variantes gráficas), eventualmente com mais prestígio, uma vez que se trata de uma palavra de origem culta. Após o período medieval, não deverá ter sido bem aceite pela massa falante, uma vez que apenas se preservou a forma ordenar e seus derivados. Também a forma (a)mjrgulhar (e variantes) deve ter sido estigmatizada a partir de 1450, ao passo que uirtude e testimunho conheceriam na segunda metade do século XV alguma vitalidade. Quanto a mjlhor e direito, apresentam uma significativa progressão a partir do século XVI, devendo ter favorecido a consagração pela norma da forma direito (dereito, em galego) a contiguidade de um fonema consonântico alveolar e outro

representação da nasal palatal e não de alveolar. Como se trata de formas isoladas, não incluiremos no tratamento estatístico as formas ligumes, coonjgo, Marichal, pireira e Ffyrnão.

24 As últimas abonações com $i$ átono, para os dois tipos, são as seguintes: ordynações (1433 Ped 90) e hordjnairo (1405 MA 70). 
dental. Para além destas formas, houve aquelas que, no leque cronológico abrangido por este estudo (e, ao contrário do que, posteriormente, a norma culta da língua veio a aceitar) apenas conheceram [i] como vogal pretónica, como poffiffam e Giraldo, provando, assim, que a aceitação/valoração social depende, em muitos casos, da pressão linguística.

\subsubsection{Elevação de /e/ devido à harmonização vocálica}

Vejamos agora o outro tipo de situação, que diz respeito a casos especiais dependentes do condicionamento exercido pelo contexto, ou seja, a casos em que /e/ se eleva, em virtude dos fenómenos de harmonização vocálicas. ${ }^{25}$ Convém salientar que, em algumas formas verbais (no tema de presente), o fenómeno já se encontra largamente documentado em documentos em galego anteriores a 1260 :

«nos nosos documentos tamém se rexistra vacilación entre formas de tipo queria (4 ocorrencias) e quiria (5 ocorrencias), onde se produce asimilación ao [i] tónico. Similarmente, rexístrase dezia/dizia, midia. O mesmo fenómeno pode darse tamém nas formas arrizotónicas do pretérito dos verbos regulares: pidio/pidiron/pedeu; pediron; recibi/recebi» (Boullón Agrelo / Monteagudo 2009: 24).

Apresentamos a seguir os exemplos ilustrativos do fenómeno de assimilação exercido por $i$, que foi possível extrair do nosso corpus. ${ }^{26}$ Lembramos que a primeira

25 Incluímos no mesmo grupo quer os casos em que a vogal $e$ sofre assimilação da vogal da sílaba tónica quer da vogal que a precede imediatamente. Excecionalmente, é a vogal postónica que sofre assimilação: ẽtrin/iqua (1490 MA 131, 2 v.), por exemplo.

26 Poderá questionar-se se o vocalismo pretónico de formas como sigujfe, figujnte, figuifem, figujda, figujnte, figujntes, Jjgjnte se deverá explicar por assimilação vocálica ao timbre da vogal da sílaba tónica ou se estas formas resultam do efeito nivelador da analogia com a primeira pessoa do singular do presente do indicativo e com as três pessoas do singular e do plural do presente do conjuntivo. Veja-se a equacionação deste problema em Maia: 831, nota 1. As formas fyntirem (1485 MA 128) e cõjjntjmẽto (1532 Tur 149), extraídas do nosso corpus, não ajudam no esclarecimento do problema, pelo seu carácter tardio e pelo facto de se documentar apenas [con]fento (1352 Ped 38), em época arcaica. Por outro lado, a nossa coleção documental apresenta ainda, em textos relativamente tardios, as variantes com e etimológico fegue (1485 MA 128) e fege (1491 Alj 132). É possível que o vocalismo átono de Jyntir e cõfjntjr (ou derivado, atrás referido) se deva ao efeito assimilatório da vogal da sílaba tónica do infinitivo. Ramón Lorenzo apresenta inúmeros exemplos de formas com este vocalismo (quer na forma verbal infinitiva quer no nome deverbal), não só na Traducción gallega de la Crónica General (...), como em outros textos literários: Crónica Geral de Espanha, Crónica Troyana, etc. Cf. Lorenzo, II (Glosario), s.u. "consentir" e "consintemento". Ana Maria Martins coloca o problema nestes termos: "É natural supor (...) que se tenha criado ao lado do paradigma flexional com vogal radical etimológica, um outro paradigma flexional construído a partir dos infinitivos com vogal radical [+ alt]. (...) As formas synto (..), sirvo (..), sirvamos (..), sigamos (...), poderiam integrar paradigmas deste tipo". Cf. Martins (1988: 363). A explicação ainda não está suficientemente 
abonação registada data de 1350 (pidyou), tornando-se a partir daí bastante frequentes os exemplos:

Arripiado (1356 MA 41), aujriã (1502 MA 137), avyria (1502 MA 137), Biringell (1459 MA 111, 3 v.), conhiçim[ẽ]to (1467 Mai 117), conhjçja (1428 Alj 86), conhjçjmẽto (1428 Alj 86, 3 v.), cõfjntjmẽto (1532 Tur 149), difinitiua (1412 Ped 74), defobidientes (1436 Alf 93), detjrmjnhado (1434 SC 91), dyrrybar (1430 Cós 89), évi/tidos (1509 Ped 140), espycyall (1536 SC 150), espiçial (1379 Alc 51; 1453 MA 107), espiçiall (1440 MA 96; 1478 MA 123; 1479 MA 124 e 1485 MA 128; 1521 Ped 143), efpiçyaees (1495 MA 134), efpicyall (1495 MA 134), efpycjal (1422 MA 82), efpycyal (1437 Ped 94), ẽviftidos (1509 Ped 140), faliçymento (1495 MA 134), freeguifia (1408 MA 71), freguifia (1362 MA 44; 1363 MA 45; 1399 MA 65), fregujffya (1453 MA 107), mitia (1527 MA 146), Mjnjno (1491 Alj 132), mjtidos (1509 Ped 140), mjtydoo (1467 Mai 117), nigligẽcia (1397 MA 63; 1410 MA 73), nigligencia (1413 MA 75), njgligençias (1453 MA 107), njgrijençjas (1419 MA 79), obidientes (1436 Alf 93), ofericida (1460 MA 113), pidia (1353 Vid 39; 1421 Evo 80; 1452 MA 106; 1495 MA 134), pidĩdo (1438 Ped 95), pidio (1421 Evo 80; 1442 SM 97 e 1515 SM 141), pidir (1405 MA 70; 1405 MA 70, 2 v.; 1421 Evo 80; 1437 Ped 94), pidirã (1428 MA 87; 1489 MA 130; 1528 MA 147), pidiram (1522 MA 144), pidirão (1527 MA 146), pidirõ (1383 Alj 53; 1405 MA 70; 1495 MA 134; 1502 MA 137; 1505 MA 138), pidirom (1438 Ped 95 e 1500 MA 136), pidja (1435 Alj 92), pidjdo (1435 Alj 92), pidjdos (1428 Alj 86), pidjr (1383 Alj 53; 1435 Alj 92), pidjuo (1435 Alj 92), pidya (1451 MA 105, 2 v.; 1460 MA 113), pidyou (1350 AM 36; 1351 Alv 37), pidyrrõ (1507 MA 139), pidyu (1460 MA 113), pilitaría (1391 MA 59), pilitaria (1428 MA 87), piljtaria (1392 MA 60), pitiçã (1565 Alc 153), pitiçõ (1352 Ped 38; 1379 Alc 51), pitições (1379 Alc 51), pitintees (1460 MA 113), pjdja (1435 Alj 92; 1491 Alj 132), pobiricafe (1435 Alj 92), pproçjdjmentos (1491 Alj 133), promitjãm (1532 Tur 149), pydja (1491 Alj 132), pydjmos (1491 Alj 133, 2 v.), pydjo (1491 Alj 133), pydjram (1430 Cós 89), pydymos (1491 Alj 133), Pymytell (1507 MA 139), quiria (1402 Ped 68, 3 v.), quiriam (1402 Ped 68), rigiftrada (1345 MA 33), rrequirido (1526 Ped 145), rrequiridos (1526 Ped 145), rrequjrjmẽto (1435 Alj 92, 2 v.), rrequjrya

fundamentada, embora pareça ter uma certa coerência argumentativa aquela que José Joaquim Nunes apresenta: fundamentando-se em documentos escritos nos fins do século XIV, regista que nestes textos começam a surgir formas que atestam o hábito de, nos verbos da $3^{\text {a }}$ conjugação, se assimilar à vogal tónica - $i$ - do infinitivo o e do radical átono. Em vez de ferir, medir, pedir, etc., passou a pronunciar-se firir, midir, pidir, etc. (Nunes 1989: § 32, 286-287). Quanto às formas flexionais e derivadas de conhocer, houve assimilação vocálica em dois graus: conhocimento $>$ conhecimento $>$ conhicimento. 
(1487 PP 129), rrequjrymẽto (1487 PP 129, 3 v.), seruỹtjas (1521 Ped 143), sigujfe (1460 MA 113), figuj̃te (1428 MA 87), figuifem (1460 MA 113), Jigujda (1460 MA 113), figujnte (1428 MA 87, 2 v.), Jigujntes (1428 MA 87), Jjgjnte (1383 Alj 53), Spicial (1403 MA 69; 1405 MA 70 e 1482 MA

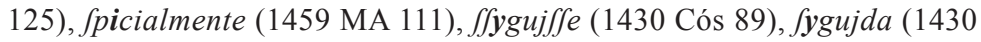
Cós 89), fyntirem (1485 MA 128), tindeiras (1528 MA 147), traujfya (1502 MA 137) e viftyaria (1500 MA 136).

Partindo da forma mais representada no nosso corpus (pedir e variantes gráficas, flexionais e derivadas), apresentamos a seguir a evolução do fenómeno da harmonização vocálica, ao longo do eixo temporal:

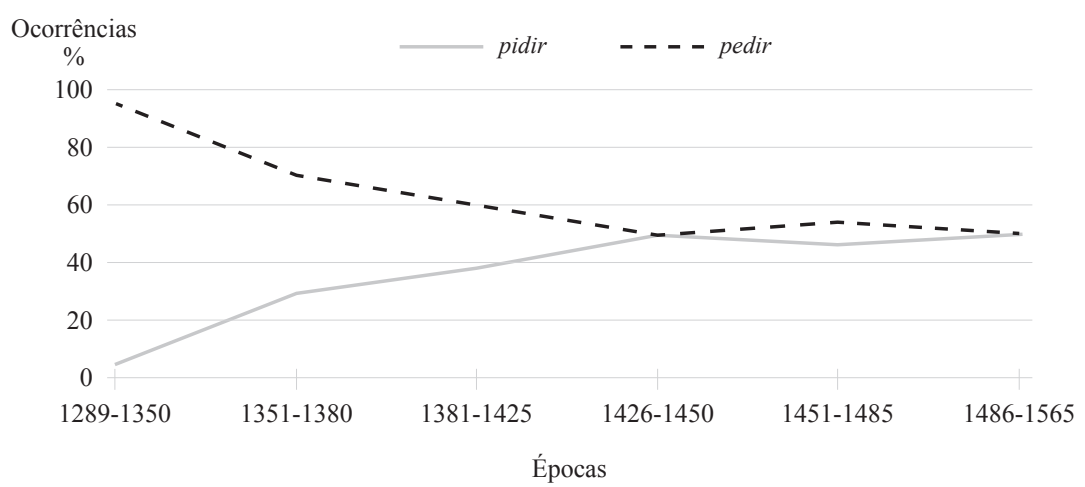

Figura $\mathrm{n}^{\circ} 3$ - Cronologia da harmonização vocálica na forma pedir (variantes gráficas e flexionais) e derivados.

O gráfico mostra, claramente, que a partir do segundo quartel do século XV a percentagem de formas que revela harmonização vocálica é muito idêntica ao das etimológicas, o que ajuda a explicar a vitalidade do fenómeno no português do Brasil.

Também na amostra da região em estudo se verificam alguns exemplos que evidenciam a tendência registada nos textos galegos, e que corresponde "a uma alteração muito frequente nos idiomas hispânicos ocidentais" (Maia 1997: 370) para o e em sílaba pretónica aparecer substituído por $u$, por um processo assimilatório favorecido pela contiguidade de um fonema velar. Na quase totalidade dos nossos exemplos (que correspondem a variantes da mesma forma), surge $u$ em vez de $e$, quando esta vogal vem seguida de consoante velar, naturalmente com mais afinidades articulatórias com aquela vogal. É igualmente possível que essa influência da consoante velar tenha atuado simultaneamente à assimilação ao timbre da pretónica seguinte, mas em algumas variantes, por deturpação popular, 
esse timbre alterou-se para $a$, após a vogal ter exercido a influência assimilatória ${ }^{27}$. Analisemos os exemplos:

eixucaçã (1422 MA 82; 1429 MA 88), emxucotor (1491 Alj 133), enxucaçã (1502 MA 137), enxисаçom (1495 MA 134), exисaçõ (1450 Alv 104; 1452 MA 106; 1453 MA 107, 2 v.), éxucoçõ (1477 MA 121; 1478 MA 122; 1478 MA 123; 1479 MA 124; 1484 MA 126; 1485 MA 128), exисoçom (1465 MA 116), ехисис̧ã (1519 MA 142), exиquaçã (1489 MA 130), exиquaçõ (1442

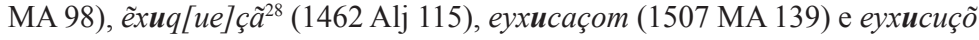
(1500 MA 136).

Outros casos evidenciam a influência do contexto consonântico a que já aludimos (aliado, eventualmente, a uma assimilação vocálica): trata-se da forma lugumes (1465 MA 116), que apresenta $u$ em vez de $e$, quando essa vogal vem seguida de consoante velar. Outros exemplos, ainda que escassos, mostram que quando em contato com labial, $e$ átono pretónico cedeu lugar a $u$, tal como já foi referido por Clarinda de

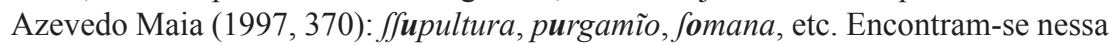
situação, no nosso corpus, as formas pulgamjnho (1383 Alj 53), purgaminho (1350 AM 36) e teftomõio ${ }^{29}$ (1297 Alc 5).

\subsection{Difusão da realização [i] para /e/ átono}

Tentaremos agora demonstrar que uma realização de /e/ diferente de [e] e idêntica ou muito próxima de [i] atual é também já muito antiga na língua, tendo-se difundido a partir do último quartel do século XV. Assim, é nossa convicção que a atual pronúncia [i] se divulgou na zona Centro e Sul com a mesma celeridade que nos falares setentrionais. Efetivamente, os exemplos com síncope de e pretónico, mais numerosos no nosso corpus do que em $H G P$, são suficientes para admitir que não constituem lapsos de copistas mas formas reais vivas da época, que já exibiam a redução e (eventualmente) o fechamento de $e$ :

27 Saliente-se que essa assimilação de $e$ por $u$ e simultânea alteração para $a$ da vogal que provocou assimilação tem uma cronologia bem definida: de 1397 a 1413 registaram-se 10 ocorrências da forma execuçõ (excepcionalmente, execuçom). A partir dessa data e até 1519 as formas que se encontram nos textos revelam sistematicamente a vogal $u$ em vez de $e$ nesse contexto, surgindo muitas vezes substituída por $a$ a vogal que provocou a assimilação. Só num documento de 1529 volta a aparecer a forma (etimológica) execuçam (1529 MA 148).

28 Neste caso, registou-se uma permuta entre as vogais, tal como (entre vogal e ditongo) em ceyrelaría e ceyrelaria (1304 Alc 10).

29 Formas deste tipo (que sofreram labialização) existem no galego popular oral (Ferreiro 1999: 52). A leitura da última forma é duvidosa. 


$\begin{array}{ll}\text { Data/Doc. } & \text { Formas } \\ \text { 1304 Alc 9 } & \text { podrofo } \\ \text { 1336 Alj 26 } & \text { eqriçõ } \\ \text { 1399 MA 65 } & \text { tabliom } \\ \text { 1426 MA 85 } & \text { rreçbeo } \\ \text { 1482 MA 125 } & \text { acõtçer; bnẽffiçiado } \\ \text { 1490 MA 131 } & \text { bcharell }^{31} \\ \text { 1496 Sal 135 } & \text { dzanoue } \\ \text { 1505 MA 138 } & \text { parçeo } \\ \text { 1526 Ped 145 } & \text { bneffiçiado bnẽffyçiado } \\ & \text { bnefficiados (3 v.); bneffyçiados } \\ & \text { dzasete; bneffiçio; ffzese } \\ \text { rrceberã }\end{array}$

Tabela $\mathrm{n}^{\mathrm{o}} 4$ - Formas que evidenciam redução ou desaparecimento de $e$ átono

Os exemplos acima apresentados, mais frequentes a partir do último quartel do século XV, confirmam inequivocamente que, quando seguido de alveolar (menos frequentemente de palatal), /e/ pretónico começava a corresponder a uma pronúncia bastante relaxada que se refletia na grafia, com o seu desaparecimento.

Também na forma contraída que resultou de PER ǏLLU(M), a partir de finais do século $\mathrm{XIV}, \mathrm{o}[\mathrm{e}]$ tendeu a reduzir-se ou mesmo a desaparecer $($ per + la ou lo $>$ pella $/-o>$ pllo $)$. Ou seja, a partir de certa altura, pelo e pela poderiam eventualmente ser atualizados como [plu] e [pla]. A possível redução da vogal verificou-se, sobretudo, em finais do século XIV, primeiro quartel do século XV, como revelam as abonações registadas ${ }^{32}$.

\begin{tabular}{lc} 
Data/Doc. & Formas \\
1383 Alj 53 & pllo \\
1409 MA 72 & pla \\
1416 MA 78 & plla \\
1423 MA 83 & plla \\
1429 MA 88 & plla \\
\hline
\end{tabular}

Tabela $\mathrm{n}^{\circ} 5$ - Formas que evidenciam redução ou desaparecimento de [e] em pello/- $a$

$30 \mathrm{O}$ mesmo fenómeno de síncope neste lexema ocorre num documento do século XIII em $H G P$. Cf. Maia (1997: 360).

31 Esta forma revela, certamente, o resultado da dissimilação da vogal átona inicial (bacharel > *becharel), que sofreu posteriormente um enfraquecimento que levou à síncope. Tratou-se de um fenómeno certamente favorecido pela contiguidade de um fonema palatal.

32 Não poderemos rejeitar liminarmente o facto de elas apresentarem falta de sinal de abreviatura, mas a sua cronologia, quando aliada a formas congéneres, que analisaremos a seguir, leva-nos a considerá-las como formas reais, vivas, da época. O motivo da redução desta vogal prende-se com o facto de se tratar de uma forma que ocorre em contexto átono, o que aproxima a vogal da sílaba tónica de uma vogal átona pretónica. Embora saibamos que a consideração da tonicidade destas formas seja um assunto discutível, ficará fora do escopo deste estudo. De salientar que nos três últimos documentos acima citados essas formas convivem com as que têm sobreposto um sinal de abreviatura. 
Os dados apresentados parecem ser interessantes ao fazer coincidir a data do primeiro documento que revela o desaparecimento (precedido de um fechamento de [e], eventualmente em [i]]) com o ano de 1383, início da crise de 1383-1385, que culminou com a célebre batalha de Aljubarrota, em $1385^{33}$.

O mesmo é possível inferir, com contornos cronológicos bastante nítidos, de formas em que essa vogal está entravada por nasal. De facto, a forma nẽhũu e variantes (flexionais e gráficas) era usada de modo praticamente exclusivo até cerca do final do primeiro quartel do século XV, mas a partir dessa altura começa a evidenciar a síncope dessa vogal. Analisemos os seguintes exemplos:

\begin{tabular}{|c|c|c|}
\hline Data/Doc. & Formas $^{34}$ & $\%$ \\
\hline 1423 MA 83 & nhũu; nhũa & 100 \\
\hline 1426 MA 85 & nhน̃a (2 v.); nhũus & 100 \\
\hline 1428 MA 87 & nhuus & 100 \\
\hline 1438 Ped 95 & пhи̃u & 100 \\
\hline 1440 MA 96 & nhũua (2 v.) & 100 \\
\hline 1443 Alf 99 & nhũua & 100 \\
\hline 1447 Alj 101 & nhũu & 100 \\
\hline 1465 MA 116 & nhũua & 100 \\
\hline 1472 TC 120 & nhũua & 100 \\
\hline 1490 MA 131 & nhũm; nhũa (2 v.) & 100 \\
\hline 1495 MA 134 & nhũa (2 v.) & 100 \\
\hline 1522 MA 144 & nhũa (2 v.) & 100 \\
\hline 1528 MA 147 & nhũa & 100 \\
\hline
\end{tabular}

Tabela $\mathrm{n}^{\circ} 6$ - Formas que apresentam síncope de $e$ átono, quando entravado por nasal

Não são seguramente lapsos dos copistas, que as usam de forma exclusiva nos documentos em que surgem, as abundantes formas que apresentámos acima. O facto de só começarem a surgir a partir de certa época, assim como a existência das formas, relativamente coevas ao seu advento no texto escrito, njhũa (1405 MA 70, 2 v.), njhua (1428 Alj 86) e njhũa (1437 Ped 94), conduzem a pensar que deve ter havido o alofone [i], neste contexto. Todos estes dados nos levam, assim, a discordar de Sílvio Elia para quem «em relação às vogais pretônicas, mesmo no séc. XVI, não é realmente de admitir a existência do [ë]. A oscilação era entre $e$ e $i$ » (Elia 1981: 203). Esta redução vocálica, já verificada em documentos da primitiva região

33 Inúmeras mudanças, em todos os domínios da língua, registaram-se precisamente em finais do século XIV, como consequência da mobilidade populacional que esta crise despoletou. Essas mudanças foram assinaladas e descritas nas teses de mestrado e doutoramento da Autora (Carvalho 1996, 2006), inéditas.

$34 \mathrm{O} h$ pode ser a representação de uma semivogal. 
galego-portuguesa, foi igualmente extensiva à língua do Centro, paralelamente a outras alterações linguísticas.

É, portanto, neste momento nossa convicção que /e/ pretónico deverá ter tido, ao longo do período medieval, os alofones [ej], [e] e [i] e, paralelamente a este último ou ligeiramente mais tardiamente, [i]]. Estes dados vêm, portanto, tornar mais rigorosa a cronologia proposta por Paul Teyssier, a que já aludimos.

\section{4. /e/ átono em posição pretónica, em hiato com a vogal tónica}

Analisaremos de seguida a cronologia da realização [i] de /e/ da sílaba pretónica, quando se encontra em hiato com a vogal da sílaba tónica. Convém salientar que as formas criar $^{35}$ e seus derivados assim como o antropónimo Lionardo evidenciam, sistematicamente, ao longo do corpus, a vogal $i$ :

criado (1343 AM 31; 1402 MA 67, 2 v.; 1408 MA 71; 1412 Ped 74; 1413 MA 75; 1434 SC 91; 1442 SM 97; 1444 Alv 100; 1477 MA 121; 1484 MA 127), criados (1422 MA 82; 1425 MA 84; 1490 MA 131), criança (1307 Alp 13), criar (1291 Alc 2; 1460 MA 112), criedef(1291 Alc 3), criem (1460 MA 112; 1479 MA 124), Lionard' (1428 MA 87), Ljonardo (1428 Alj 86) e Lyonarde (1380 Alv 52).

Consideremos os outros exemplos:

adiante (1355 Cel 40; 1405 MA 70; 1428 MA 87; 1452 MA 106; 1478 MA 122; 1478 MA 123; 1479 MA 124; 1484 MA 126; 1485 MA 128), adiãte (1438 Ped 95), adjante (1366 MA 46; 1428 Alj 86; 1435 Alj 92; 1442 MA 98; 1462 Alj 115; 1515 SM 141), adyante (1459 MA 110; 1477 MA 121; 1487 PP 129), adyãte (1462 Mai 114; 1467 Mai 117), [con]thiudo (1489 MA 130), conthudo (1455 MA 108), contiudas (1452 MA 106, 2 v.), contíudas (1453 MA 107), contiudo (1452 MA 106), [con]tjhudo (1435 Alj 92), corryeiro (1521 Ped 143), [cõ]tiudas (1356 MA 41, 3 v.), cõtíudas (1362 MA 43, 3 v.), [cõ]tíudo (1438 Ped 95, 2 v.), cõtjudas (1419 MA 79, 2 v.), diãmte (1440 MA 96), diamte (1442 SM 97; 1529 MA 148), diante (1386 MA 55; 1405 MA 70; 1410 MA 73, 2 v.; 1423 MA 83, 2v.; 1428 MA 87; 1444 Alv 100; 1452 MA 106, 3 v.; 1453 MA 107; 1459 MA 110; 1459 MA 111; 1460 MA 112; 1465 MA 116, 3 v.; 1471 MA 119; 1477 MA 121, 2 v.; 1478 MA 122, 2 v.; 1478 MA 123; 1479 MA 124, 2 v.; 1482 MA 125, 2 v.; 1484 MA 126, 3 v.; 1489 MA 130, 2 v.; 1490 MA 131, 3 v.; 1495 MA 134, 3 v.; 1500 MA 136; 1522 MA 144; 1528 MA 147), diãte (1438 Ped 95, 2 v.; 1447 Alj 101; 1453 MA 107; 1505 MA 138; 1529 MA 148), diente (1453 MA 107, 2 v.; 1527 MA 146), diẽte (1519 MA 142), djamte (1521 Ped 143), djante (1366 MA 46; 1419 MA

35 Saliente-se que, no galego, "aínda modernamente, non é difícil documentar vacilacións como criar crear" (Ferreiro 1999: 83). 
79; 1442 MA 98; 1455 MA 108 e 1456 MA 109, 3 v.), djãtj (1532 Tur 149), dyamte (1467 Mai 117; 1502 MA 137; 1541 Sal 152), dyãte (1467 Mai 117, 2 v.), dyemte (1536 SC 150), dyẽte (1519 MA 142), tiudos (1453 MA 107), tjor (1455 MA 108), ujeer (1448 Alj 103), ujer (1519 MA 142), ujerem (1460 MA 112), viador, 'vedor' (1541 Sal 152), vier (1465 MA 116; 1484 MA 126; 1490 MA 131), viera (1490 MA 131; 1515 SM 141), vierẽ (1469 Cel 118; 1528 MA 147, 2 v.), vierem (1465 MA 116; 1477 MA 121, 2 v.; 1479 MA 124; 1484 MA 126, 2 v.; 1522 MA 144; 1527 MA 146; 1529 MA 148, 2 v.), vieren (1527 MA 146), vierõ (1438 Ped 95; 1490 MA 131), vierrẽ (1489 MA 130), viefem (1467 Mai 117), vyera (1515 SM 141) e vyerẽ (1529 MA 148).

Selecionaremos a seguir as formas gráficas das três unidades lexicais que se encontram mais representados nos documentos: ${ }^{36}$ (a) diante, contiudo (e respetivas variantes gráficas) bem como formas de imperfeito e futuro do conjuntivo do verbo $v i r$, a fim de precisar a cronologia da passagem de $e$ a $i$ nesse contexto. A esse propósito, importa relembrar o seguinte excerto de $H G P$ :

As formas com $i$, nestes séculos [XV e XVI] como nos anteriores, são verdadeiramente esporádicas. Sobre os notários pesava a influência do latim jurídico e a tradição da língua escrita dos séculos anteriores, assim como a influência de modelos literários ou semi-literários que, neste caso concreto, contribuíam para continuar a usar o grafema $e$, apesar do desajuste porventura existente entre as formas gráficas e as correspondentes formas da língua falada (Maia ${ }^{2}$ 1997: 369).

Analisemos, esquematicamente, a cronologia desse fenómeno, por etapas epocais:

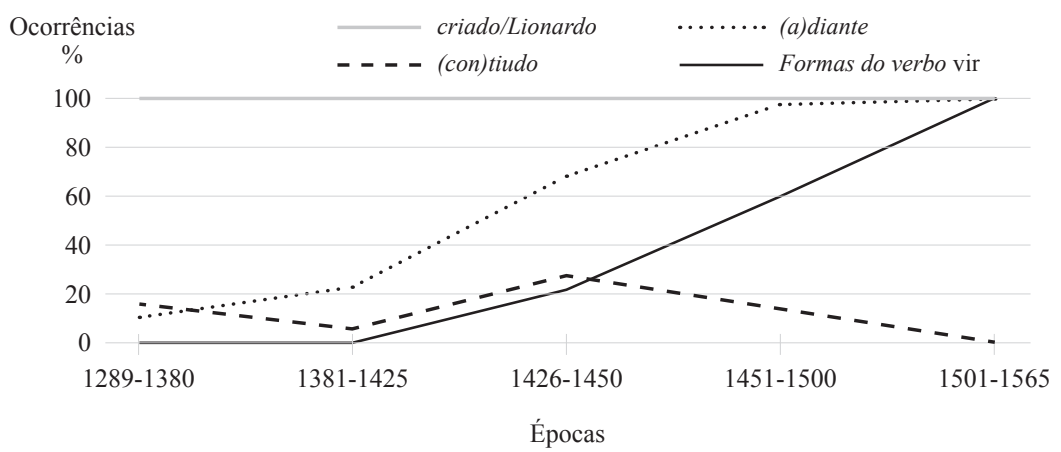

Figura $\mathrm{n}^{\circ} 4$ - Cronologia do fechamento de $e$ pretónico em hiato, em vários tipos de unidades lexicais

36 Saliente-se que o nome próprio Lionardo (e variantes) nunca aparece na variante com $e$. Por outro lado, a forma tjor (1455 MA 108) constitui um caso completamente isolado, ao lado de 27 ocorrências de theor, existentes neste corpus. 
Da análise do gráfico pode depreender-se que, à exceção da forma contiudo ${ }^{37}$, a partir de meados do século XV, a tendência dominante é o fechamento de /e/, em hiato com a vogal seguinte ${ }^{38}$, especialmente quando essa vogal se encontra precedida de dental, contexto que parece ter favorecido esse fechamento ${ }^{39}$. Embora não contempladas no gráfico, dada a escassez de documentos com esses exemplos, as formas seguintes comprovam essa constatação, bem como a cronologia apresentada:

paredeeiros (1386 MA 56), paredééiros (1386 MA 56), paredeeyros (1386 MA 56), pardyeiro (1448 Alj 103), pardieyro (1453 MA 107) e pardieiros (1528 MA 147, 5 v.).

Alguns indícios da variação registada no interior do mesmo texto, a partir dessa altura, podem verificar-se nos seguintes exemplos: diante e adeante (1460 MA 112), ou ainda viefem e veerem, 2 v. (1467 Mai 117).

Revela-se, igualmente, interessante a forma, única ao longo do corpus, rraial (1448 Alj 103) uma vez que apresenta uma outra solução para eliminar o hiato entre $e$ e $a$ : a assimilação da vogal pretónica à vogal da sílaba tónica, acompanhada de desenvolvimento de uma semivogal.

\section{5 /e/ átono em posição postónica, e em hiato com a vogal tónica $^{40}$}

Nesta posição, em contexto em que /e/ vem precedido de vibrante, registam-se três ocorrências tardias (de um lexema que designa um ponto cardeal), com elevação e fechamento da vogal: abrigo (1500 MA 136) e abriguo (1522 MA 144, 2 v.) 'áfrico' (vento) $(<$ AFRǏCU-).

Em sílaba postónica em hiato, $e$ apresenta-se desde cedo substituído por $i$, tal como hoje, nas formas em que essa alteração se traduziu igualmente numa mudança gráfica. Já em finais do século XIV, duzea (1372 MA 47) e duzeas (1386 MA 55,

37 A Autora de $H G P$ afirma ser difícil de precisar o momento em que $e$ passa a vogal assilábica nesse contexto. O que ressalta no nosso corpus é a maior incidência da vogal $i$ nesta forma precisamente no período (cronologicamente curto) compreendido entre 1426 e 1450, cujos documentos são maioritariamente oriundos dos coutos.

38 Um contexto que parece ter favorecido o fechamento foi a contiguidade de uma consoante alveolar ou dental.

39 Revela-se mais lenta a mudança quando $e$ vem precedido de fricativa labiodental, como nas formas de vir.

40 De acordo com Ferreiro (1999: 89), "En posición postónica, existe vacilación entre a conservación do hiato, a asimilación e posterior crase e mais a formación dun ditongo crecente, con fixación gráfica irregular" (femea > femia e fema, dialetal; codea > codia e coda, dialetal; gemeo > xémeo). 
6 v. e 1419 MA 79) alternavam com duzias (1383 Alj 53; 1392 MA 60 e 1397 MA 64), mas não possuímos abonações posteriores a 1419 que nos permitam extrair conclusões mais seguras sobre o timbre vocálico neste contexto.

Cremos que o que há de mais importante a referir relativamente a /e/ em posição postónica (<I) é o facto de, em algumas formas, e em certas unidades lexicais, surgir $e$ em vez de $i$ em hiato com outra vogal ou eventualmente já sem valor silábico. Trata-se, na nossa opinião, de uma hipercorrecção gráfica, que deixa entrever algumas conclusões sobre o valor de $e$ em posição postónica em hiato. Estão nessa situação, por exemplo, as formas mortoreo (1485 MA 128, 5 v.), p[ropr]ea (1462 Mai 114) e rremedeo (1467 Mai 117 e 1536 SC 150), que nunca exibem a variante com $i$. A partir do último quartel do século $\mathrm{XV}$ a forma cartoreo alterna com cartorio: cartoreo (1482 MA 125 e 1519 MA 142) cartorio (1489 MA 130 e 1529 MA 148). A mesma oscilação se pode observar em neçefario e variantes (incluindo as que apresentam dissimilação de $e$ pretónico), que se regista em textos situados entre 1372 e 1529 . Porém, a partir do terceiro quartel do século XV alguns textos exibem neçeffareo (1482 MA 125 e 1536 SC 150), correspondendo estas últimas formas a uma percentagem de $15 \%$ no total da coleção. Aproximadamente a mesma percentagem (14\%) se aplica às formas raras priujlegeo (1452 MA 106 e 1453 MA 107) e priujlegeos (1442 MA 98 e 1519 MA 142), que se podem observar num leque cronológico situado entre 1340 e 1528 . A mesma oscilação se verifica em açerfforeo (1482 MA 125) e açeforeo (1519 MA 142) acefforjo (1489 MA 130), aceforjo (1495 MA 134), acefforio (1500 MA 136 e 1502 MA 137) e acefforyo (1507 MA 139). Ora, se os tabeliães de finais do século XV escrevem estas formas com $e$, é porque já nessa altura é o mesmo o valor fónico de $e$ e $i$ nesse contexto, o que poderá constituir mais um argumento a favor da hipótese, lançada anteriormente, a propósito do valor de $e$ átono postónico.

É interessante salientar que foram encontradas formas esporádicas que apresentam a grafia ey, o que prova mais uma vez que entre [e] e [i] em posição de hiato poderiam existir matizes intermédios. Assim, não revelarão as formas eçefforejo (1478 MA 122) e emxequeyas (1491 Alj 133) uma hesitação gráfica na representação dessa oscilação fónica? De acordo com Herculano de Carvalho, trata-se de um assunto que, ao confrontar vários passos da obra de Fernão de Oliveira, afirma ficar "inteiramente em aberto" (Carvalho 1962: 7). Transcrevemos a seguir a dedução feita pelo Autor à obra de Fernão de Oliveira:

estas modalidades pequenas não constituem «letras» por si, - ao contrário de $e$ e $o$ pequenos, letras distintas de $e$ e $o$ grandes (abertos) -, mas são apenas variantes que, por outro lado, se identificam com outras tantas variantes de $e$ e $o$ pequenos. Quer dizer que nas palavras glória e continuar - que, segundo 
o gramático, seria preferível se escrevessem glórea e continoar - as 'figuras' $i$ (ou melhor, $e$ ), $u$ (ou melhor, $o$ ) corresponderiam na realização a certos sons vocálicos indefinidos, cuja impressão auditiva se situaria entre a produzida por $e$ fechado e $i$, e por $o$ fechado e $u$ respectivamente (Carvalho 1962: 8).

O Autor admite, porém, que não se detém "a analisar miudamente esses passos - o que nos levaria muito longe" (Carvalho 1962: 7). Efetivamente, os testemunhos que apresentámos acima vêm mostrar que na mente dos copistas essas "modalidades pequenas" tinham valor de [i] ou de um alofone muito próximo desse som, tal como já foi referido por este Autor (Carvalho 1962: 8-9). Deste modo, a consciência fónica de timbres muito próximos nesse contexto de hiato dava lugar a fenómenos de ultra-correcção e hesitações gráficas que levaram, a partir de meados do século $\mathrm{XV}$, em vários actos de escrita, à oscilação entre $e$ e $i$.

\section{$2.6 / \mathbf{i} / \sim / e /$ em posição final não absoluta: terminação $-u i l /-u e l^{41}$}

Observemos agora a flutuação registada na vogal da terminação - vil, -vel de palavras que representam formas latinas terminadas em -BILLE. A situação verificada nos textos sob análise confirma a preferência das formas em -uil/-ujl(l) até ao começo do século $\mathrm{XV}$, não obstante a tendência inicial (de finais do século XIII) ter sido -uel: entre 1291 e 1391 contam-se 9 formas, que se apresentam a seguir:

amiguauel (1391 MA 59), cõuenhauel (1291 Alc 2), eftauel (1298 Alc 6), mouel (1305 Alp 11 e 1307 Alp 13), perdurauel (1291 Alc 2 e 1300 Alj 8), plaziuel (1291 Alc 3) e Jtauel (1391 MA 59).

As formas em -uil/-ujl(l) situam-se entre 1304 e 1405, ou seja, surgem mais tarde nos textos, prolongando-se igualmente até um pouco mais tarde. Contam-se 15 ocorrências:

amigauil (1304 Alc 10), amjguaujll (1402 MA 67), coujnhauil (1379 Alc 51), eftauil (1328 Alj 21 e 1379 Alc 51), eftaujll (1402 MA 67), furtiuilmẽt[e] (1329 Evo 22, 2 v.), inrreuocabil (1388 MA 57), inrreuocauil (1399 MA 65), peffoauilm[ẽ]te (1321 Alc 17), ftauil (1388 MA 57 e 1399 MA 65) e ftaujl (1385 MA 54 e 1405 MA 70).

Sabemos, de acordo com o corpus em análise, que a partir de 1434 a grafia se estabilizou em -uel(l)/-vell ${ }^{42}$, o que vem confirmar a cronologia já proposta em 1996

\footnotetext{
41 Sobre a forma e função do sufixo - uel no galego medieval, veja-se Mariño Paz (2005: 155-193).

42 Foram as seguintes as abonações encontradas, a partir dessa data: amigavell (1490 MA 131 e 1490 MA 131), amjgauel (1438 Ped 95), amjgauell (1434 SC 91 e 1448 Alj 103), amjgavell (1490 MA 131, 2 v.),
} 
para as formas de plural (em -uees, que veio substituir -viis/-vis), que deve ter sido a mesma ${ }^{43}$ Posteriormente a essa data, conhecemos apenas um indício de variação opcional: trata-se do tabelião "Pedro Aluarez" que, para além de usar as formas com $i$ final $q[u]$ ity, ljuri e firmj em documentos de 1440 e 1443, emprega num dos documentos a forma eftauell e no outro eftaujll. Em traços gerais, as tendências por grandes etapas epocais são as seguintes:

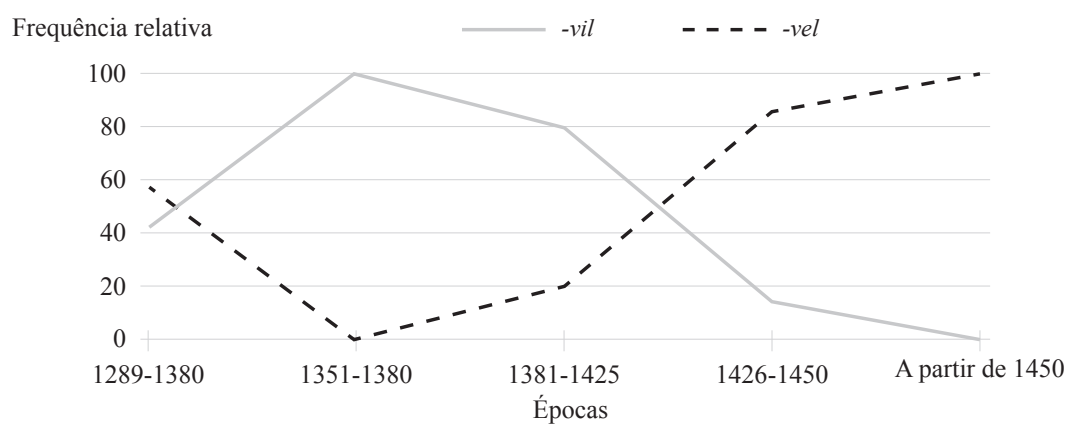

Figura $n^{\circ} 5$ - Evolução das terminações -vil/-vel, por etapas epocais

\section{Conclusões}

Em posição inicial absoluta, /e/ podia realizar-se, no Português medieval, como [e], [i] ou [ej]. Uma tendência para reforçar a vogal átona em posição inicial absoluta parece ter sido a sua nasalização em [ẽ] (a partir de finais do século XIV, com uma

çiuel (1565 Alc 153), eftauel (1438 Ped 95), eftauell (1434 SC 91 e 1440 MA 96), jnrreuogauell (1484 MA 127), mouell (1529 MA 148; 1536 SC 150, 2 v. e 1536 SC 151) e ýrreuoguauell (1521 Ped 143).

43 Carvalho (1996: 136-137): “A preferência dos autores quatrocentistas vai para os plurais em -vees, pelo que deve ter sido esta a terminação que adquiriu mais prestígio na língua escrita». Esperança Cardeira corrobora esta constatação, salientando o seguinte: «Esta substituição [de -vil por -vel] verifica-se no primeiro quartel do século XV e fixa-se no segundo quartel do mesmo século, embora ainda se registem formas em -vil nos anos seguintes (...). Se, no entanto, compararmos os resultados do Livro da Cartuxa com os da documentação não literária, veremos que enquanto nestes documentos, entre 1425 e 1450, a frequência de lexemas em -vel (singular e plural) é apenas, ainda, de 64.3\%, no Livro da Cartuxa estas formas já substituíram completamente as antigas terminações em -vil". Quanto às Vidas de Santos, refere que "as formas em -vel perfazem 91.1\% do total". Tal constatação permite-lhe concluir: "Sendo a grafia destes textos, como já vimos, conservadora em outras variáveis estudadas, a elevada percentagem de formas inovadoras, que se aproxima, neste caso, da Cartuxa, leva-nos a confirmar que para esta substituição muito contribuiu o uso preferencial da terminação -vel nos textos de carácter literário. Tratou-se, pois, de uma variação opcional, dependente do estilo textual; o prestígio que a variante em -vel adquiriu devido à sua selecção nos textos literários terá determinado o desaparecimento da antiga variante em -vil". Cf. Cardeira (2005: 279). 
frequência mais acentuada a partir da segunda metade do século seguinte), em muitos casos em formas onde também se regista ei/ey, nesse contexto. Vimos também que, em alguns casos, en- e $e i$ - foram evoluções divergentes que ainda aparecem contemporaneamente, quer no português, quer no galego. Por outro lado, en em posição inicial teve tendência a elevar-se, podendo igualmente oscilar com vogal nasal anterior fechada [ĩ], em textos de finais do século XV. Assim se justificam as formas istar e intrar no Português do Brasil, referidas por Paul Teyssier (1980: 103).

A cronologia da elevação das vogais átonas mediais, situada no século XVIII por Carvalho e Teyssier, deverá recuar-se em mais de quatro séculos, uma vez que, como ficou demonstrado, houve lexemas e formas antroponímicas que revelaram desde sempre [i] em posição átona pretónica: Giral, Giraldiz/Giraldez e poffiffõ(es), por exemplo. O fenómeno parecia estar em incubação, já no século XIII, tendo encontrado condições linguísticas favoráveis à sua difusão, quando em contato com consoante palatal ou alveolar: coonjgo, Ffyrnão, hordinada, Marichal, mjlhor, ordinhamos são exemplos que atravessam os séculos e que ilustram esta situação. As formas de pretérito e tempos afins do verbo irregular fazer com vogal radical /i/ não tiveram (pelo menos, na escrita) a mesma celeridade evolutiva, eventualmente pela proximidade de um fonema fricativo labial, que neutralizou essa tendência. Foi a partir do último quartel do século XIV que começaram a proliferar formas onde atuaram simultaneamente os contextos vocálico e consonântico no fechamento da vogal: ordinhairo, hordinajro, mjlhoria, direito, (a)mirgulhar, testimunha, pireira, ligumes, etc. $\mathrm{O}$ contexto consonântico parece ter sido mais importante ainda que o contexto vocálico, uma vez que /e/ nunca aparece com a realização [i] em fegura, e apenas tardiamente em uertude. A este respeito, parece ter havido uma hierarquização no léxico quanto à aceitação social de [i]: algumas palavras de origem culta retomariam o $<\mathrm{e}>$ a partir do $2^{\circ}$ quartel do século XV; outras retomá-lo-iam a partir de 1450. Simultaneamente, o $<\mathrm{i}>$ difundiu-se noutras a partir dessa data: as formas mjlhor e direito apresentam uma significativa progressão a partir do século XVI. Esta diferença de ritmos na difusão de [i] prova, portanto, que a aceitação/ valoração social depende, em muitos casos, da pressão linguística (e da combinação articulatória dos sons), sendo, por isso, um processo com dimensão cognitiva.

Outro tipo de situação diz respeito a casos especiais dependentes do condicionamento exercido pelo contexto, ou seja, aqueles em que /e/ se eleva, em virtude do fenómeno de harmonização vocálica. O fenómeno, extremamente comum em documentos galegos anteriores a 1260, começou a alastrar na zona Centro a partir de 1350, sendo que a partir de 1425 pedir e pidir parecem ter progredido com igual intensidade.

Uma realização de /e/ diferente de [e] e idêntica ou muito próxima de [i] atual é também já muito antiga na língua, tendo-se difundido a partir do último quartel do 
século XV. De facto, quando seguido de alveolar (menos frequentemente de palatal), /e/ pretónico começava a corresponder a uma pronúncia bastante relaxada que se refletia na grafia, com o seu desaparecimento: podrofo, ẽqriçõ, tabliom, rreçbeo, acõtçer são alguns exemplos. O mesmo é possível inferir de formas em que essa vogal está entravada por nasal. De facto, a forma nẽhũu e variantes (flexionais e gráficas) era usada de modo praticamente exclusivo até cerca do final do primeiro quartel do século XV, mas a partir dessa altura começa a evidenciar a síncope dessa vogal: nhũu; nhũa (2 v.); nhũus, nhuus são alguns exemplos. A existência das formas, relativamente coevas ao seu advento no texto escrito: njhua (1428) e njhũa (1405, 2 v.; 1437) conduzem a pensar que deve ter havido o alofone intermédio [i], neste contexto. É, portanto, neste momento nossa convicção que /e/ pretónico deverá ter tido, ao longo do período medieval, os alofones [ej], [e] e [i] e, paralelamente a este último ou ligeiramente mais tardiamente, [i]. Estes dados vêm, portanto, ultrapassar a cronologia proposta por Paul Teyssier, a que atrás aludimos.

Quanto a /e/ átono em posição pretónica, em hiato com a vogal tónica, convém salientar que as formas criar e seus derivados assim como o antropónimo Lionardo evidenciam, sistematicamente, ao longo de todo o período abrangido por este estudo, a vogal $i$. A partir de meados do século XV, regista-se a tendência para o fechamento de /e/, em hiato com a vogal seguinte, especialmente quando essa vogal se encontra precedida de dental, contexto que parece ter favorecido esse fechamento (diante, por exemplo). A partir do último quartel do século $\mathrm{XV}$, regista-se a flutuação cartoreo $\sim$ cartorio; necessareo $\sim$ necessario, priuilegio $\sim$ priuilegeo, etc. É interessante salientar que foram encontradas formas esporádicas que apresentam a grafia ey (eçefforejo 1478 e emxequeyas 1491), o que prova mais uma vez que entre [e] e [i] em posição de hiato poderiam existir matizes intermédios. Vacilações entre -io e -eo persistem ainda no galego e no português atual.

A situação verificada nos textos sob análise confirma a preferência das formas em -uil/-ujl(l) até ao começo do século XV, não obstante a tendência inicial (de finais do século XIII) ter sido -uel. A grafia estabilizou-se em -uel(l)/-vell a partir da década de 30 daquele século, mas ainda na década de 40 o tabelião "Pedro Aluarez", para além de usar as formas com $i$ final q[u]ity, ljuri e firmj em documentos de 1440 e 1443, emprega num dos documentos a forma eftauell e no outro eftaujll.

Em suma, por tudo quanto fica exposto, é legítimo compreender o fenómeno da

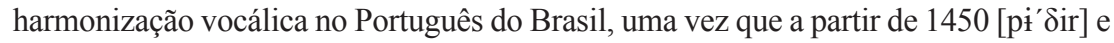
[pi'dzir] caminharam a par. Quanto à redução e fechamento de /e/ átono em [i] parece ter-se difundido no Português a partir de 1480. Assim, mesmo que este traço tivesse sido transportado para o Brasil por um colonizador que nascesse por essa altura, não tinha decorrido o tempo suficiente para ter sido convencionalizado pela norma culta. 
Não é de excluir, por outro lado, a possibilidade de este fenómeno ter recuado, em contato com os falares indígenas, ou de outros povos que aí confluiriam.

\section{Referências bibliográficas}

Boullón Agrelo, A. I. 1 (2013): “A edición da documentación medieval non literaria en Galicia”, em Álvarez, R. / Martins, A. M. / Monteagudo, H. / Ramos, M. A. (eds.), Ao sabor do texto. Estudos dedicados a Ivo Castro, 57-76 (Santiago de Compostela: Servizo de Publicacións e Intercambio Científico da Universidade de Santiago de Compostela).

Boullón Agrelo, A. I. / Monteagudo, H. (2009): De verbo a verbo: documentos en galego anteriores a 1260. Anexo 65 de Verba. Anuario galego de Filoloxía. (Santiago de Compostela: Servizo de Publicacións e Intercambio Científico da Universidade de Santiago de Compostela).

Cardeira, E. (2005): Entre o Português Antigo e o Português Clássico (Lisboa: Imprensa Nacional - Casa da Moeda).

Carvalho, J. G. Herculano de (1962): "Nota sobre o vocalismo antigo português: valor dos grafemas $e$ e $o$ em sílaba átona". Separ. de Revista Portuguesa de Filologia XII/1, 1-23. [reed. em Herculano de Carvalho, J. G. (1984), Estudos Linguísticos, vol. II, 77-103] (Coimbra: Coimbra Editora)].

Carvalho, M. J. (1999): “A alomorfia no plural dos nomes e adjetivos de lexema em -l: um estudo de morfologia histórica portuguesa", em Lopes, A. C. Macário / Martins, A. M. (orgs.), Actas do XIV Encontro Nacional da Associação Portuguesa de Linguística (Aveiro, 28-30 de Setembro de 1998), vol. I, 265-281 (Braga: Associação Portuguesa de Linguística).

Carvalho, M. J. S. Pereira de (2006): Documentação medieval do mosteiro de Santa Maria de Alcobaça (sécs. XIII-XVI). Edição e estudo linguístico. Dissertação de doutoramento, apresentada à Faculdade de Letras de Coimbra (Coimbra: Faculdade de Letras da Universidade de Coimbra) [inédita].

Carvalho, M. J. Simões Pereira de (1996): Do Português arcaico ao Português moderno. Contributos para uma nova proposta de periodização. Dissertação de mestrado em Linguística Portuguesa, apresentada à Faculdade de Letras da Universidade de Coimbra (Coimbra: Faculdade de Letras da Universidade de Coimbra) [inédita].

Carvalho, M. J. (2005): "On the Origin of the Final Unstressed [i] in Brazilien and Other Varieties of Portuguese. New Evidence in an Enduring Debate", em Mogensen, J. E. / Skafte Jensen, E. / Fortescue, M. / Shøsler, L. (eds.), Historical Linguistics 2003. Selected Papers from the 16th International Conference on Historical Linguistics (Copenhagen, 11-15 th August, 2003), 47-60 (Amsterdam / Philadelphia: John Benjamins Publishing Company). 
Castro, I. (1993): “A elaboração da língua portuguesa, no tempo do Infante D. Pedro", em Actas do Congresso Comemorativo do $6^{\circ}$ Centenário do Infante D. Pedro (25 a 27 de Novembro de 1992) (= Biblos 69), 97-106.

Castro, I. (Com a colaboração de Rita Marquilhas e J. Léon Acosta) (1991): Curso de história da língua portuguesa (Lisboa: Universidade Aberta).

Coelho, J. do Prado (1946): "Para o estudo da pronúncia do português medieval”, Revista de Portugal. Série A - Língua Portuguesa 10, 217-221.

Elia, S. (1981): “A pronúncia quinhentista do português”, em Macchiaroli, G. (ed.), Atti del XIV Congresso Internazionale di Linguistica e Filologia Romanza (Napoli, 15-20 Aprile 1974), vol. 5, 197-219 (Amsterdam: John Benjamins).

Ferreiro, M. (1999) [1995]: Gramática histórica galega. I. Fonética e Morfosintaxe (Santiago de Compostela: Edicións Laiovento).

García de Diego, V. (1909): Elementos de gramática histórica gallega (Fonética-Morfología) (Burgos: Imp, y Lib. de los Hijos de Santiago Rodríguez).

Hart, T. R. (1955): Notes on Sixteenth-Century Portuguese Pronunciation, Word 11/3.

Hart, T. (1959): "The Overseas Dialects as Sources for the History of Portuguese Pronunciation", em Actas do III Colóquio Internacional de estudos Luso-Brasileiros (1957), vol. I, 161-272 (Lisboa).

Gonçalves, M. F. Moreira (1999): A morfologia verbal do Galego-Português. Contributos para um estudo sincrónico-descritivo. Dissertação de mestrado em Linguística Portuguesa, apresentada à Faculdade de Letras da Universidade de Coimbra (Coimbra: Faculdade de Letras da Universidade de Coimbra) [inédita].

Kabatek, J. (2001): “¿Cómo investigar las tradiciones discursivas medievales? El ejemplo de los textos jurídicos castellanos", em Jacob, D. / Kabatek, J. (orgs.), Lengua medieval y tradiciones discursivas en la Península Ibérica: descipción gramatical - pragmática histórica - metodologia, 97-132 (Frankfurt-Main / Madrid: Verwert / Iberoamericana).

Lorenzo, R. (1977): La traducción gallega de la Crónica General y de la Crónica de Castilla. Edición crítica anotada, com introducción, índice onomástico y glosario, vol. II. Glosario (Orense: Instituto de Estudios Orensanos "Padre Feijoo").

Lorenzo, R. (2007): "Os notários e a língua nos comezos da escrita documental en galego", em Boullón Agrelo, A. I. (ed.), Na nosa lyngoage galega. A emerxencia do galego como lingua escrita na Idade Média, 313-372 (Santiago de Compostela: Consello da Cultura Galega / Instituto da Lingua Galega).

Machado, J. P. (1995) [1952]: Dicionário etimológico da língua portuguesa, 5 vols. (Lisboa: Livros Horizonte). 
Maia, C. de Azevedo (1997) [1986]: História do galego-português. Estado linguístico da Galiza e do Noroeste de Portugal desde o século XIII ao século XVI. Com referência à situação do galego moderno (Lisboa: JNICT e FCG).

Mariño Paz, R. (2009): “A vogal /i/ em posición átona final de palabra no galego medieval”, Revista de Filología Románica 26, 71-98.

Mariño Paz, R. (2005): "Forma e función do sufixo -uel no galego medieval”, Cadernos de língua 27, 155-193.

Nunes, J. J. (1989) [1919]: Compêndio de gramática histórica portuguesa (Fonética e Morfologia) (Lisboa: Livraria Clássica Editora).

Martins, A. M. (1988): "Metafonia verbal no português - uma abordagem histórica", em Kremer, D. (ed.), Homenagem a Joseph M. Piel por ocasião do seu $85^{\circ}$ aniversário, 349-366 (Tübingen: Max Niemeyer Verlag).

Martins, A. M. (2003-2006): "Para a história do vocalismo átono português: a propósito do 'Testamento de D. Afonso II de 1214'”, Revista Portuguesa de Filologia. Miscelânea de Estudos In Memoriam José G. Herculano de Carvalho 25/1, 295-319 (Coimbra: Instituto de Língua e Literatura Portuguesas. Faculdade de Letras da Universidade de Coimbra).

Naro, A. (1971): "The History of $e$ and $o$ in Portuguese: a Study in Linguistic Drift", Language 47, 615-645. Trad. port. de Campos, L. / Santos, K. E. (1973): “A história do $e$ e do $o$ em português: um estudo de deriva linguística", Estudos Diacrônicos, 9-51 (Petrópolis: Vozes).

Révah, I. S. (1959): “Comment et jusqu' à quell point les parlers brésiliens permettent-ils de reconstituer le système phonétique des parlers portugais des XVI ${ }^{\text {ème }}$-XVII ${ }^{\text {ème }}$ siècles?", em Actas do III Colóquio de Estudos Luso-Brasileiros, vol. I, 261-272 (Lisboa).

Révah, I. S. (1958): "L'évolution de la prononciation au Portugal et au Brésil du XV ème siècle à nos jours", em Anais do Primeiro Congresso Brasileiro de Língua Falada no Teatro, 387-399 (Rio de Janeiro).

Silva, A. da Conceição de Almeida e (1998): O sistema verbal do português arcaico. O papel da analogia na regularização dos paradigmas verbais do português arcaico da segunda fase. Dissertação de mestrado em Linguística Portuguesa, apresentada à Faculdade de Letras da Universidade de Coimbra (Coimbra: Faculdade de Letras) [inédita].

Teyssier, Paul (1980): Histoire de la langue portugaise (Paris: Presses Universitaires de France). Trad. port. de Cunha, C. (1982) : História da língua portguesa (Lisboa: Sá da Costa). 
